Supporting information

\title{
Folding Paper-Based Aptasensor Platform Coated with Novel Nanoassemblies for Instant and Highly Sensitive Detection of $17 \beta$-Estradiol
}

\author{
Tao Ming ${ }^{1,2}$, Yang Wang ${ }^{1,2}$, Jinping Luo ${ }^{1,2}$, Juntao Liu ${ }^{1,2}$, Shuai Sun ${ }^{1,2}$, Yu Xing ${ }^{1,2}$, Guihua Xiao ${ }^{1,2}$, Hongyan \\ $\mathrm{Jin}^{3^{*}}$, Xinxia Cai ${ }^{1,2^{*}}$ \\ ${ }^{1}$ State Key Laboratory of Transducer Technology, Institute of Electronics, Chinese Academy of Sciences, Beijing 100190, PR \\ China \\ ${ }^{2}$ University of Chinese Academy of Sciences, Beijing 100049, PR China \\ ${ }^{3}$ Obstetrics and Gynecology Department, First Hospital Peking University, Beijing 100034, China \\ *Corresponding Email: maggijhy@163.com (H.Jin), xxcai@mail.ie.ac.cn \\ KEYWORDS: Folding Aptasensor Platform; Microfluidic Channel; Paper-based Device; Novel Nanoassembly; $17 \beta$-estradiol
}



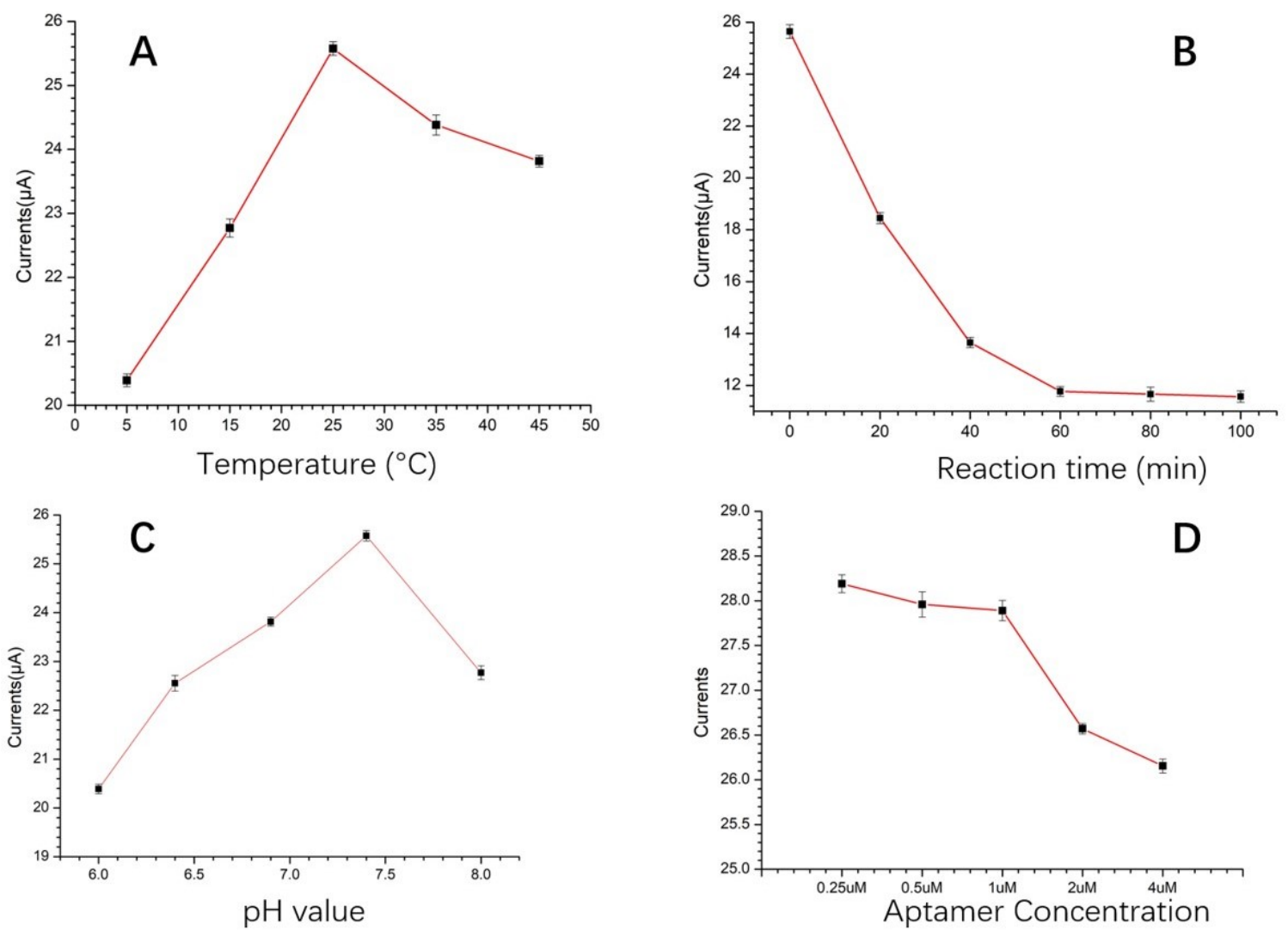

Figure S1. The optimization experiments of reaction parameters: (a) The temperature range from $5^{\circ} \mathrm{C}$ to $45^{\circ} \mathrm{C}$, (b) The reaction time range from 0 min to 100 mins, (c) the $p H$ value range from 6.0 to 8.0, (d) the aptamer concentration range from $0.25 \mu \mathrm{M}$ to $4 \mu \mathrm{M}$.

As shown in Figure $\mathrm{S} 1 \mathrm{~A}$ and Figure $\mathrm{S} 1 \mathrm{C}$, the best results were achieved at $25^{\circ} \mathrm{C}$ and $\mathrm{pH}$ 7.4. As shown in Figure $\mathrm{S} 1 \mathrm{~B}$, a reaction time of $60 \mathrm{~min}$ allowed E2 $(1 \mathrm{ng} / \mathrm{mL})$ and the aptamer to sufficiently bind. The optimal aptamer concentration was $1 \mu \mathrm{M}$ (Figure S1D). 


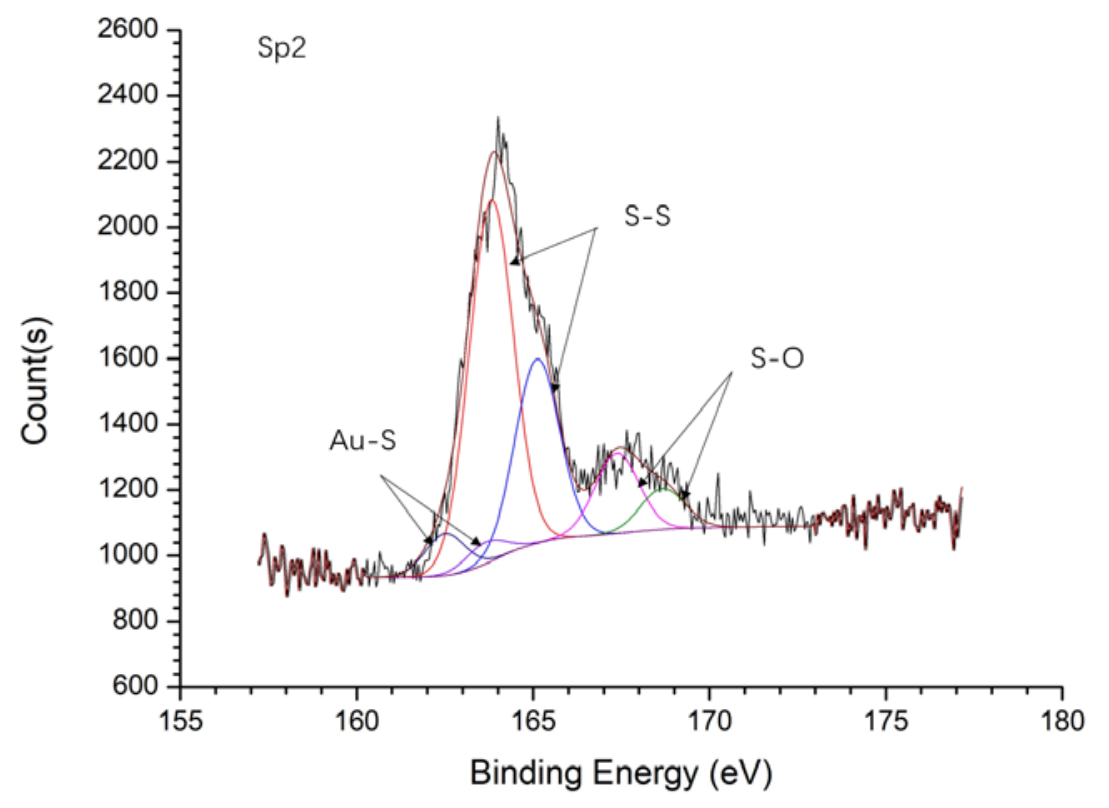

Figure S2. X-Ray photoelectron spectroscopy spectrum detailed spectra of Sp2.

The binding energy peaks lie at $165.26 \mathrm{eV}$ and $163.71 \mathrm{eV}$ for $\mathrm{S}_{2 \mathrm{p} 3 / 2}$ and $\mathrm{S}_{2 \mathrm{p} 1 / 2}$ indicates the existence of Au-S bond ${ }^{1}$. Thus, the immobilization of the aptamer on the AuNPs was checked and characterized. 


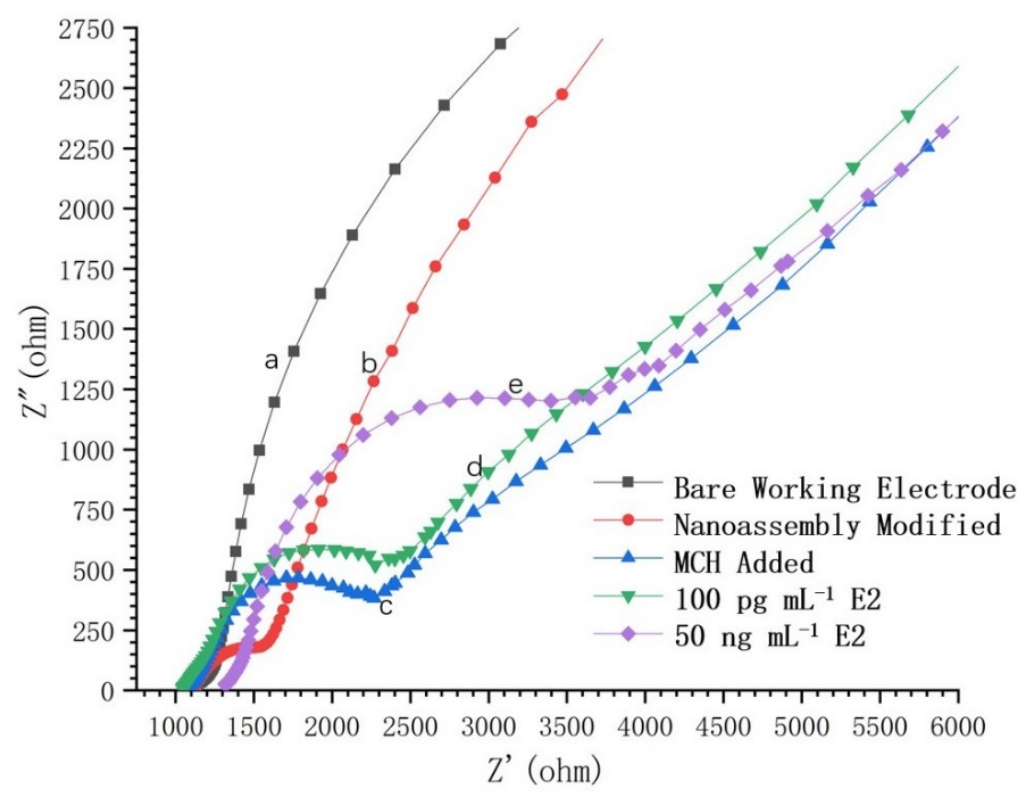

Figure S3. EIS of the layer-by-layer assembly of sensor platforms: (a) bare working electrode, (b) modified by Nanoassembly, (c) modified by $\mathrm{MCH}$, (d) binding with 100pg $\mathrm{mL}^{-1} 17 \beta$-E2, (e) binding with $50 \mathrm{ng} \mathrm{mL} \mathrm{L}^{-1} 17 \beta$-E2

The result of Nyquist plots for the working electrode with different layers were shown in Fig.S3. Compared with bare electrode, after modification with nanoassemblies, the impedance of the working electrode dropped significantly. However, after modified with $\mathrm{MCH}$, the impedance increased. And after combing with $17 \beta$-E2, the impedance increased gradually, which was consistent with the principle of the method.

\section{Reference:}

(1).Besharat, Z.; Wakeham, D.; Johnson, C. M.; Luengo, G. S.; Greaves, A.; Odnevall Wallinder, I.; Gothelid, M.; Rutland, M. W., Mixed monolayers of alkane thiols with polar terminal group on gold: Investigation of structure dependent surface properties. J Colloid Interface Sci 2016, 484, 279-290. 
